\title{
Difference in biofilm development capability of vancomycin and ciprofloxacin resistant Staphylococcus aureus clinical isolates
}

\author{
Husain Saify, Rakesh Kumar Patidar, Mayuri Khare, K. N. Sahare and Vinod Singh* \\ *Correspondence: vsingh3@rediffmail.com \\ Department of Microbiology, Barkatullah University, Bhopal, Madhya Pradesh, India.
}

\begin{abstract}
Background: Staphylococcus aureus has long been recognized as a major pathogen of urinary tract and hospital acquired infections. Over the last decade antibiotic resistance and biofilm formation potential by pathogens is a major challenge. In this study we screened S. aureus clinical isolates by antimicrobial susceptibilty and biofilm assays to determine biofilm capability of vancomycin and ciprofloxacin resistant isolates.

Methods: Six clinical isolates of S. aureus were characterized by biochemical tests and further antibiotic susceptibility of vancomycin and ciprofloxacin were tested against $S$. aureus clinical isolates by disc diffusion method. Biofilm formation capability of these isolates were performed by microtiter plate, coverslip congored agar and tube assays.

Results and disscusion: In this study we found that two isolates were resistant to ciprofloxacin and three isolates were resistant to vancomycin, on the basis of CLSI guidelines. Ciprofloxacin resistant isolates showed moderate biofilm formation while vancomycin resistant showed strong biofilm formation.

Conclusion: We have concluded that ciprofloxacin and vancomycin resistant clinical isolates were showed differences in biofilm formation. Staphylococcal isolates having biofilm propensity exhibit more resistance to antibiotics, hence are difficult to treat.

Keywords: Antibiotic, biofilm, ciprofloxacin, resistance, vancomycin
\end{abstract}

\section{Introduction}

Staphylococcus aureus is a gram positive cocci normally localize in the skin and mucous membranes in the nasal area of healthy humans and about $30 \%$ of the normal healthy population are transiently colonized by the organism [1]. These bacteria are associated with the several syndromes such as skin infections, osteomyelitis, bacteraemia, septicaemia, diarrhea, pneumonia and urinary tract infections [2-8]. Biofilm formation is the potential and major virulence trait [9] and has been described as a possible attribute to the resistance and major contributor to several infections. Biofilm impairs the action of both host immune system and antimicrobial activities. The formation of biofilms is an excellent example of a phenotypic change in S. aureus to adapt to its surroundings in the presence of environmental challenges and is a recognized method of some microorganism's capability to cause certain infections, and a way by which they increases its levels of antimicrobial resistance [10]. It is now well documented that biofilms are difficult to eradicate and are often resistant to systemic antibiotic therapy and removal of abiotic surfaces becomes necessary [11]. The differentiation of Staphylococci with respect to its biofilm phenotype might help in diagnosis of infections related to hospital devices and prevention of device related infections [12]

The pathogenesis of Staphylococcal infection begins with primary attachment and colonization of the host tissues. Once a biofilm has been formed, it is a major concern for clinicians in the treatment of infectious disease because of multi drug resistance [13]. Therefore, a better understanding of bacterial biofilms is urgently needed, and this may ultimately result in the development of novel therapeutics for the control of infections [14].

In this study we have screened S. aureus clinical isolates by antimicrobial susceptibilty and biofilm assays to determine biofilm capability of vancomycin and ciprofloxacin resistant isolates.

\section{Materials and methods \\ Bacterial isolates}

In this study, urine samples were collected the patients of Hamidia hospital, Bhopal, India. Out of 32 isolates, 11 isolates were identified as Gram positive Staphylococci. Further identification of these isolates was done by catalase, coagulase, sugar fermentation tests and cultivation on blood agar, mannitol salt agar, CLED agar. Out of 11 Staphylococci isolates, 6 were Staphylococcus aureus and 5 were coagulase negative Staphylococci. Staphylococcus aureus MTCC 3160 strain was used as a control in the whole study.

\section{Antibiotic susceptibility testing}

The antibiotic-resistance profile of $S$. aureus strains against ciprofloxacin $(5 \mu \mathrm{g})$ and vancomycin $(30 \mu \mathrm{g})$ was determined by the disc diffusion assay [15]. Mueller-Hinton agar plates were overlaid with the inoculum (turbidity equivalent to that of a 0.5 McFarland Standard) of the S. aureus clinical strains. Antibiotic susceptibility was established and measured by the reference criteria of Clinical and Laboratory Standards 
Saify et al. Research Journal of Infectious Diseases 2013,

Table 1. Distribution of antibiotic susceptibility and biofilm formation capability of $S$. aureus clinical isoates against ciprofloxacin.

\begin{tabular}{llcccc}
\hline Isolates & Ciprofloxacin & $\begin{array}{l}\text { Congo red } \\
\text { agar assay }\end{array}$ & $\begin{array}{l}\text { Tube } \\
\text { assay }\end{array}$ & $\begin{array}{l}\text { Microtiter } \\
\text { assay }\end{array}$ & $\begin{array}{l}\text { Coverslip } \\
\text { assay }\end{array}$ \\
\hline SA1 & Sensitive & + & + & + & + \\
SA2 & Resistant & ++ & ++ & ++ & ++ \\
SA3 & Resistant & ++ & ++ & ++ & ++ \\
SA4 & Sensitive & + & + & + & + \\
SA5 & Sensitive & + & + & + & + \\
SA6 & Sensitive & + & + & + & + \\
SA MTCC 1360 & Sensitive & + & + & + & + \\
\hline
\end{tabular}

+biofilm forming, ++moderate biofilm forming.

Institute (CLSI) guidelines.

\section{Biofilm formation assay \\ Congo red agar assay}

Production of slime was studied by cultivation of all S. aureus strains on congo red agar media [16]. Briefly, the medium was composed of Brain Heart Infusion Agar (37 gms/L), sucrose $(50 \mathrm{gms} / \mathrm{L})$, and congo red stain $(0.8 \mathrm{gms} / \mathrm{L})$. Plates were inoculated and incubated aerobically for 24 to 48 hours at $37^{\circ} \mathrm{C}$. Positive result was indicated by black colonies with a dry crystalline consistency. Weak slime producers usually remained pink, though occasional darkening at the center of colonies was observed.

\section{Tube assay}

A qualitative assessment of biofilm formation was determined by tube assay [17]. Briefly, overnight culture of S. aureus isolates were inoculated in tryptic soya broth with $1 \%$ sucrose and incubated for $24 \mathrm{~h}$ at $37^{\circ} \mathrm{C}$. The tubes were removed and washed with phosphate buffer saline and dried. Tubes were stained with $0.1 \%$ crystal violet for $10 \mathrm{~min}$. Excess stain was removed and tubes were washed with distilled water. Tubes were than dried and observed for biofilm formation. Biofilm formation was considered positive when a visible film lined the wall and bottom of the tube. Ring formation at the liquid interface was not indicative of biofilm formation. Tubes were examined and the amount of biofilm formation was scored as 0-absent, 1-weak, 2-moderate or 3-strong. Experiment was performed in triplicate and repeated three times.

\section{Microtiter plate assay}

Microtiter plate method is considered as a gold standard method for the quantification of biofilm formation. Briefly, overnight culture of $S$. aureus strains was grown in brain heart infusion broth (BHI) (Himedia Laboratories, India) for $18 \mathrm{~h}$ at $37^{\circ} \mathrm{C}$. One $\mathrm{ml}$ of overnight culture was transferred to $10 \mathrm{ml}$ of sterile $\mathrm{BHI}$ broth with the addition of $1 \%$ Sucrose for biofilm development. The suspensions were adjusted with the same BHI medium to 0.5 on the McFarland turbidity standard as measured by absorbance (0.08-0.1 at $625 \mathrm{~nm}$ ) in a spectrophotometer (Shimadzu, Australia), corresponding to approximately 102 CFU/ $\mathrm{ml}$. Then, from each culture, $250 \mu \mathrm{l}$ volumes were transferred into wells of a microtiter plate (Himedia Laboratories, India). Blank wells contained broth, only. Plates were incubated for 24 hours at $37^{\circ} \mathrm{C}$. At the end of 24 hours, the planktonic suspension and nutrient solution were removed and each well was washed three times with $300 \mu$ of sterile physiological saline. The plates were vigorously shaken in order to remove planktonic cells. The remaining attached cells were fixed with $250 \mu \mathrm{l}$ of $96 \%$ ethanol per well, and after $15 \mathrm{~min}$, plates were made empty and left to dry. Each well was then stained with $200 \mu \mathrm{l}$ of $0.1 \%$ crystal violet (CV Gram stain, Merck, Germany). The stain was rinsed off by placing the plates under tap water. After drying the stained plates, biofilms were visible as purple rings formed on the sides of each well. The quantitative analysis of biofilm formation was performed by adding $200 \mu \mathrm{l}$ of $33 \%(\mathrm{v} / \mathrm{v})$ glacial acetic acid (Merck, Germany) per well. Then the optical density (OD) of the stain was observed and measured at $570 \mathrm{~nm}$ by an ELISA reader (Lisa, Germany). The isolates were classified into three categories: nonadherent (A570 $\leq 0.1)$, weakly adherent $(0.2 \geq A 570 \geq 0.1)$, strongly adherent, $(0.2<A 570)$. Experiment was performed in triplicate and repeated three times.

\section{Coverslip assay}

In coverslip assay [18], biofilms of S.aureus clinical isolates were grown as follows, individual sterile culture dishes were filled with $2.5 \mathrm{ml}$ of $\mathrm{BHI}$ broth with $1 \%$ sucrose and sterile glass coverslip was added to each petriplate. Each sample was inoculated with defined volume of overnight culture. The dishes were incubated aerobically at $37^{\circ} \mathrm{C}$ for $72 \mathrm{~h}$. Planktonic cells were rinsed off with phosphate buffer saline and sessile cells or biofilm were stained with $0.1 \%$ crystal violet for 5 min. Finally stained biofilms were observed microscopically.

\section{Results and discussion}

Staphylococcus aureus is a gram positive coccal bacterium which is highly adaptive to human environment and are resistant to several antibiotics including vancomycin, which is the last effective antibiotic against $S$. aureus. There are many resistant species of $S$. aureus out of which the most infectious strains are vancomycin resistant and ciprofloxacin resistant S. aureus. In this study we found that two isolates were resistant to ciprofloxacin and three isolates were resistant to vancomycin (Tables 1 and 2), on the basis of CLSI guidelines. Over the last few decades the continuous incresing of bacterial resistance to antimicrobials has been a cause of worldwide concern and a great challenge. This situation is provoked by over the counter accessibility, indiscriminate and inappropriate use of antimicrobial agents. Ciprofloxacin and vancomycin are the most effective known drugs against urinary tract infections. In addition biofilm formation is known 


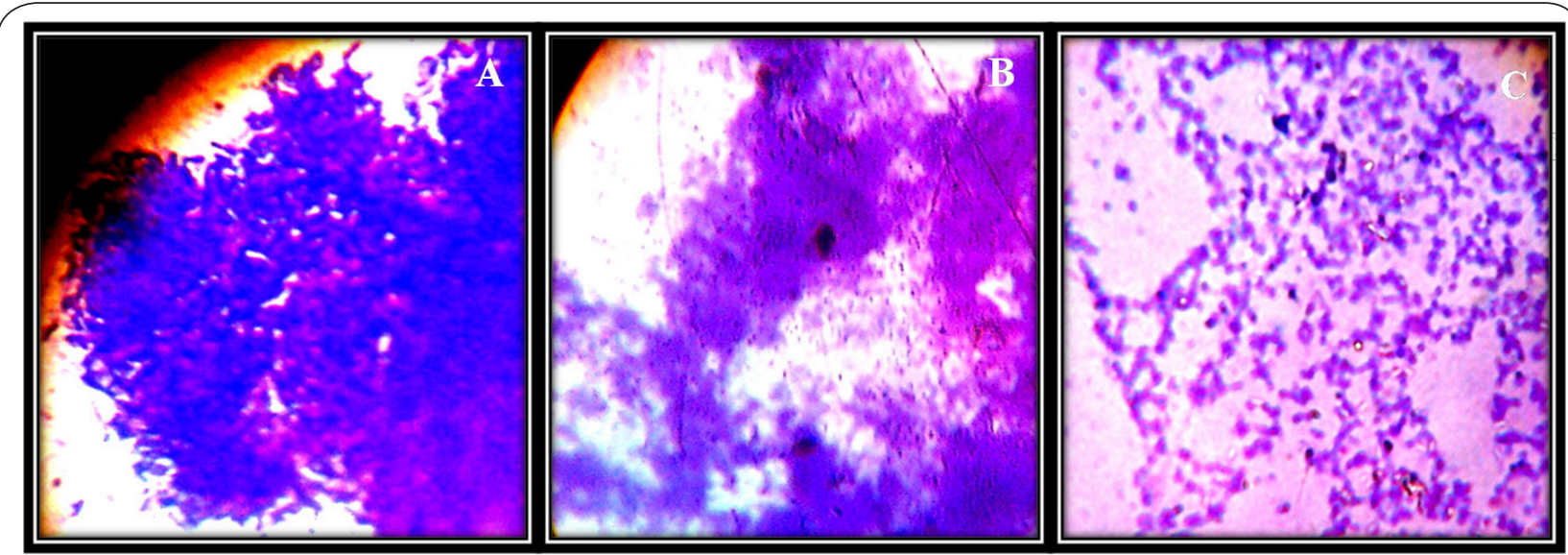

Figure 1. Shows biofilm forming capability of Vancomycin resistant (A), Ciprofloxacin resistant (B) and Sensitive (C) S.aureus isolates by coverslip assay.

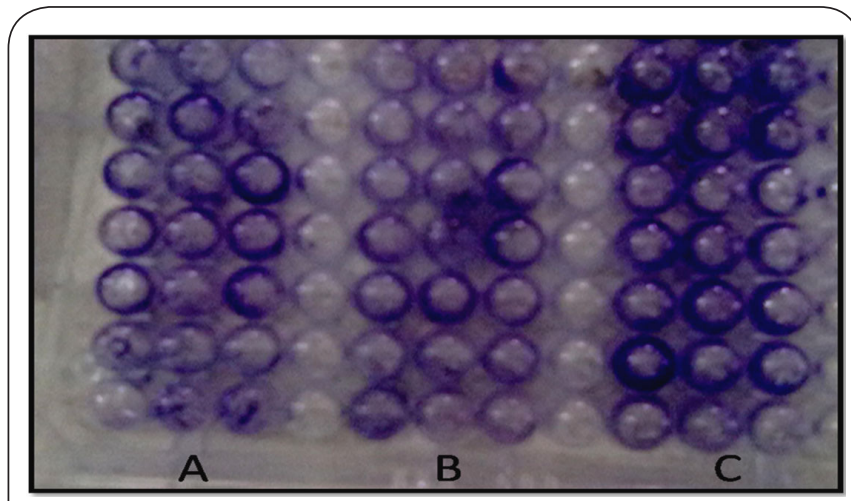

Figure 2. Shows biofilm forming capability of Ciprofloxacin resistant (A), Sensitive (B) and Vancomycin resistant (C) S. aureus isolates by microtiter plate assay.

Table 2. Distribution of antibiotic susceptibility and biofilm formation capability of $S$. aureus clinical isoates against vancomycin.

\begin{tabular}{lccccc}
\hline Isolates & Ciprofloxacin & $\begin{array}{l}\text { Congo red } \\
\text { agar assay }\end{array}$ & $\begin{array}{l}\text { Tube } \\
\text { assay }\end{array}$ & $\begin{array}{l}\text { Microtiter } \\
\text { assay }\end{array}$ & $\begin{array}{l}\text { Coverslip } \\
\text { assay }\end{array}$ \\
\hline SA1 & Sensitive & + & + & + & + \\
SA2 & Resistant & +++ & +++ & +++ & +++ \\
SA3 & Resistant & +++ & +++ & +++ & +++ \\
SA4 & Sensitive & + & + & + & + \\
SA5 & Resistant & +++ & +++ & +++ & +++ \\
SA6 & Sensitive & + & + & + & + \\
SA MTCC 1360 & Sensitive & + & + & + & + \\
\hline
\end{tabular}

+biofilm forming, ++ moderate biofilm forming, +++ trong biofilm forming.

major virulence determinant of S. aureus. In our study biofilm forming capability of ciprofloxacin and vancomycin resistant isolates showed differences in biofilm assays (Tables 1 and 2 ). Ciprofloxacin resistant isolates showed moderate biofilm formation while vancomycin resistant showed strong biofilm formation (Figures 1 and 2). Staphylococci are bacterial pathogens that usually produce biofilms during different infe-ctious processes, which are generally difficult to treat or control. It has been estimated that about 65 per cent of the nosocomial infections are associated with biofilm formation. These infections are 10 to 1000 times more difficult to eliminate with an otherwise successful treatment. The mechanism for enhanced antimicrobial resistance is believed to involve alteration or change in gene expression leading to a phenotypic difference between the planktonic and sessile condition. The sessile forms are more resistant as they produce exopolysaccharide, have different growth characteristics and take up nutrients and drugs differently from their planktonic counterparts [19].

\section{Conclusion}

We have concluded that ciprofloxacin and vancomycin resistant clinical isolates were showed differences in biofilm formation. Vancomycin resistant S. aureus isolates showed strong biofilm formation while ciprofloxacin resistant isolates showed moderate biofilm formation.

\section{Competing interests}

The authors declare that they have no competing interests.

\section{Authors' contributions}

\begin{tabular}{|l|c|c|c|c|c|}
\hline Authors' contributions & HS & RKP & MK & KNS & VS \\
\hline Research concept and design & -- & -- & -- & -- & $\checkmark$ \\
\hline Collection and/or assembly of data & $\checkmark$ & -- & -- & -- & -- \\
\hline Data analysis and interpretation & -- & $\checkmark$ & -- & $\checkmark$ & -- \\
\hline Writing the article & $\checkmark$ & $\checkmark$ & -- & -- & -- \\
\hline Critical revision of the article & -- & -- & $\checkmark$ & -- & -- \\
\hline Final approval of article & -- & -- & -- & -- & $\checkmark$ \\
\hline Statistical analysis & -- & -- & -- & $\checkmark$ & -- \\
\hline
\end{tabular}


Saify et al. Research Journal of Infectious Diseases 2013,

\section{Acknowledgement}

This study was solely supported by Barkatullah University. We would like to extend our thanks to Hamidia Hospital, Bhopal for providing clinical samples.

Publication history

EIC: Ishtiaq Qadri, King Abdul Aziz University, Saudi Arabia.

Received: 10-Oct-2013 Revised: 17-Oct-2013

Accepted: 06-Nov-2013 Published: 19-Nov-2013

\section{References}

1. Liu GY. Molecular pathogenesis of Staphylococcus aureus infection. Pediatr Res. 2009; 65:71R-77R. | Article | PubMed Abstract | PubMed Full Text

2. Tumbarello M, Tacconelli E, Lucia MB, Cauda R and Ortona L. Predictors of Staphylococcus aureus pneumonia associated with human immunodeficiency virus infection. Respir Med. 1996; 90:531-7. | Article I PubMed

3. Franzetti F, Grassini A, Piazza M, Degl'innocenti M, Bandera A, Gazzola L, Marchetti G and Gori A. Nosocomial bacterial pneumonia in HIVinfected patients: risk factors for adverse outcome and implications for rational empiric antibiotic therapy. Infection. 2006; 34:9-16. | Article | PubMed

4. Flemming $\mathrm{K}$ and Ackermann $\mathrm{G}$. Prevalence of enterotoxin producing Staphylococcus aureus in stools of patients with nosocomial diarrhea. Infection. 2007; 35:356-8. | Article | PubMed

5. Muder RR, Brennen C, Rihs JD, Wagener MM, Obman A, Stout JE and Yu VL. Isolation of Staphylococcus aureus from the urinary tract: association of isolation with symptomatic urinary tract infection and subsequent staphylococcal bacteremia. Clin Infect Dis. 2006; 42:46-50. | Article | PubMed

6. Baba-Moussa L, Anani L, Scheftel JM, Couturier M, Riegel P, Haikou N, Hounsou F, Monteil H, Sanni A and Prevost G. Virulence factors produced by strains of Staphylococcus aureus isolated from urinary tract infections. J Hosp Infect. 2008; 68:32-8. | Article | PubMed

7. Shigemura K, Tanaka K, Okada H, Nakano Y, Kinoshita S, Gotoh A, Arakawa $S$ and Fujisawa M. Pathogen occurrence and antimicrobial susceptibility of urinary tract infection cases during a 20-year period (1983-2002) at a single institution in Japan. Jpn J Infect Dis. 2005; 58:303-8. | Pdf | PubMed

8. Huggan PJ, Murdoch DR, Gallagher K and Chambers ST. Concomitant Staphylococcus aureus bacteriuria is associated with poor clinical outcome in adults with S. aureus bacteraemia. J Hosp Infect. 2008; 69:345-9. | Article | PubMed

9. Dhanawade NB, Kalorey DR, Srinivasan R, Barbuddhe SB and Kurkure NV. Detection of intercellular adhesion genes and biofilm production in Staphylococcus aureus isolated from bovine subclinical mastitis. Vet Res Commun. 2010; 34:81-9. | Article | PubMed

10. Monroe D. Looking for chinks in the armor of bacterial biofilms. PLOS Biol. 2007; 5:e307. | Article | PubMed Abstract | PubMed Full Text

11. Lewis K. Riddle of biofilm resistance. Antimicrob Agents Chemother. 2001; 45:999-1007. | Article | PubMed Abstract | PubMed Full Text

12. Raad I, Darouiche R, Hachem R, Sacilowski M and Bodey GP. Antibiotics and prevention of microbial colonization of catheters. Antimicrob Agents Chemother. 1995; 39:2397-400. | Article | PubMed Abstract | PubMed Full Text

13. Amorena B, Gracia E, Monzon M, Leiva J, Oteiza C, Perez M, Alabart JL and Hernandez-Yago J. Antibiotic susceptibility assay for Staphylococcus aureus in biofilms developed in vitro. J Antimicrob Chemother. 1999; 44:43-55. | Article | PubMed

14. Davis SC, Martinez $L$ and Kirsner R. The diabetic foot: the importance of biofilms and wound bed preparation. Curr Diab Rep. 2006; 6:439-45. I Article I PubMed

15. Bauer AW, Kirby WM, Sherris JC and Turck M. Antibiotic susceptibility testing by a standardized single disk method. Am J Clin Pathol. 1966; 45:493-6. | PubMed
16. Freeman DJ, Falkiner FR and Keane CT. New method for detecting slime production by coagulase negative staphylococci. J Clin Pathol. 1989; 42:872-4. | Article | PubMed Abstract | PubMed Full Text

17. Christensen GD, Simpson WA, Bisno AL and Beachey EH. Adherence of slime-producing strains of Staphylococcus epidermidis to smooth surfaces. Infect Immun. 1982; 37:318-26. | Article | PubMed Abstract | PubMed Full Text

18. Patidar RK, Gupta MK, Dwivedi D and Singh V. In vitro biofilm formation potential and antimicrobial sensitivity of Streptococcus mutans clinical isolates. Am J Pharmtech res. 2012; 2:551-557. | Article

19. Agarwal A and Jain A. Association between drug resistance \& production of biofilm in staphylococci. Indian J Med Res. 2012; 135:562-4. | Article | PubMed Abstract | PubMed Full Text

\section{Citation:}

Saify H, Patidar RK, Khare M, Sahare KN and Singh $V$. Difference in biofilm development capability of vancomycin and ciprofloxacin resistant staphylococcus aureus clinical isolates. Res J Infect Dis. 2013; 1:8. http://dx.doi.org/10.7243/2052-5958-1-8 